\title{
World Journal of Pediatric Surgery \\ Treatment efficacy of tolterodine versus belladonna mixture in children with idiopathic overactive bladder
}

\author{
Zheming Xu, ${ }^{\odot}$ Dehua Wu, Chang Tao, Juan Zhou, Zhihui Zheng, Daxing Tang
}

To cite: Xu Z, Wu D, Tao C, et al. Treatment efficacy of tolterodine versus belladonna mixture in children with idiopathic overactive bladder. World Jnl Ped Surgery 2019;2:e000046. doi:10.1136/ wjps-2019-000046

Received 3 March 2019 Revised 13 June 2019 Accepted 1 July 2019
Check for updates

(c) Author(s) (or their employer(s)) 2019. Re-use permitted under CC BY-NC. No commercial re-use. See rights and permissions. Published by BMJ.

Department of Urology, Children's Hospital, Zhejiang University School of Medicine, Hangzhou, China

Correspondence to Dr Daxing Tang; tangdx0206@ zju.edu.cn

\section{ABSTRACT}

Objectives Children with symptoms of urinary urgency, frequency and incontinence are common in the clinic. The aim of the present study was to compare the tolerability and efficacy of tolterodine, a bladder-selective muscarinic receptor antagonist, with belladonna mixture, a traditional anticholinergic drug, in the treatment of idiopathic overactive bladder in children.

Methods Children aged $5-10$ years with a history of diurnal urgency, frequency and incontinence were randomly divided into two groups. Participants in group 1 were given tolterodine $1 \mathrm{mg}$ twice a day for 14 days. If the results were found to be mildly ineffective, after the first 14 days of therapy, prolonged course with $2 \mathrm{mg}$ twice a day was given. In group 2, the children were treated with belladonna mixture $5 \mathrm{~mL}$ twice a day for 14 days. Anticholinergic side effects were recorded during the therapy and efficacy was evaluated with voiding diary recorded by the parents at the beginning and end of therapy.

Results A total of 668 cases were included in this study and 334 for each 25 group (496 boys and 172 girls). Evident anticholinergic side effects which could cease the therapy, such as dry mouth, constipation, mood changes, irritability, and so on, exhibited only on $2 \%$ of participants in the tolterodine group but $69 \%$ in the belladonna mixture group $(p \leq 0.05)$. The symptoms of detrusor overactivity disappeared or significantly improved in $80 \%$ of children in the tolterodine group and $37 \%$ in the belladonna mixture $(p \leq 0.05)$ group.

Conclusions Tolterodine had better tolerability and efficacy than belladonna mixture in treating overactive bladder in children.

\section{INTRODUCTION}

School-year-old children with symptoms of daytime urinary urgency, frequency with/ without wetness and incontinence are common in the clinic. ${ }^{1}$ Reports have shown that the symptoms of one or more overactive bladder $(\mathrm{OAB})$ behaviors occur in $26 \%$ of 7 -year-old children, ${ }^{2}$ and $80 \%$ of them demonstrate a reduced functional bladder capacity and/or detrusor overactivity. ${ }^{3}$ With 49 left untreated, spontaneous resolution occurs in 25\%-30\% of patients per year, which is similar to those with nocturnal
Key messages

What is already known about this subject

- The symptoms of one or more overactive bladder (OAB) behaviors occur in $26 \%$ of 7 -year-old children and $80 \%$ of them demonstrate a reduced functional bladder capacity and/or detrusor overactivity. Anticholinergic drugs including tolterodine and belladonna mixture (commonly used in China) are commonly used.

\section{What are the new findings}

- Among parents of children who received tolterodine therapy, $89 \%$ reported a significant improvement of life quality, including social skills, self-confidence, better mood, and emotional stability, while only $35 \%$ in the belladonna mixture group reported such improvements. Tolterodine had better tolerability and efficacy than belladonna mixture in treating $O A B$ in children. So use of tolterodine should not be restricted by time, it could prolong up to 3 months or more if necessary.

How might it impact on clinical practice in the foreseeable future

- In China, still belladonna mixture is commonly used in treating OAB. Belladonna mixture should be replaced with tolterodine which had tolerability and efficacy.

enuresis. ${ }^{4}$ However, it is often socially and mentally distressing, resulting in the need for the patients to modify behavior to accommodate the disability. Failure to modify behavior is currently hypothesized to be the chief cause of the Hinman-Allen syndrome (non-neurogenic bladder). ${ }^{45}$ Therefore, these children need positive and effective medical interventions in which anticholinergic drugs and behavior therapies are commonly accepted right now. The aim of the present study was to compare the tolerability and efficacy of tolterodine, a bladder-selective muscarinic receptor antagonist, and belladonna mixture (a traditional anticholinergic drug which was commonly used in pediatric clinics in China) in children with detrusor overactivity. 
Table 1 Characteristics of tolterodine and belladonna mixture groups

\begin{tabular}{llllll}
\hline \multirow{2}{*}{ Groups } & Gender & & & Age (years) & \multicolumn{2}{c}{ Course of disease (days) } \\
\cline { 2 - 3 } Tolterodine & Male & Female & & Mean (range) & Mean (range) \\
\hline Belladonna mixture & 242 & 92 & $7.5(5-10)$ & $125.1(14-180)^{*}$ \\
\hline
\end{tabular}

${ }^{*}$ The rank-sum test was used to compare the means, $p=0.072$, with no statistical significance.

\section{METHODS}

Between August 2004 and August 2018, children aged 5-10 years old with symptoms of urge incontinence suggestive of detrusor overactivity were included into this study. In this study, 668 children were randomly divided into two groups (496 boys and 172 girls, mean age 7 years, range 5-10years). Eligible children were those with symptoms of urge incontinence suggestive of detrusor overactivity (1 diurnal incontinence episode or more days out of 7 ), which last more than 2 weeks. In group 1 , the children ( 242 boys and 92 girls) start to take tolterodine $1 \mathrm{mg}$ twice a day for 14 days. If the effect was mild or there was no effect after the first 14 days' therapy, prolonged course with $2 \mathrm{mg}$ twice a day was given for another 14 days. In group 2, the children ( 254 boys and 80 girls) were treated with belladonna mixture ${ }^{6}$ containing belladonna tincture and compound vitamin B solution $5 \mathrm{~mL}$ twice a day for 14days. Pretreatment assessments were performed using physical examination, routine urine test, and ultrasound for postvoid residual (PVR) volume. Patients were excluded if they had urinary tract infection, urinary tract malformation, and neurogenic bladder. PVR volume was calculated by removing the amount of urine from the bladder capacity, those with PVR volume that was $20 \%$ or more of functional bladder capacity were also excluded. Informed consent was obtained from the parents. The side effects were recorded during the therapy, and efficacy was evaluated with voiding diary recorded by the parents at the beginning and end of therapy. The outcomes of the study were marked as: 0-completely healed, symptoms disappeared, no urinary incontinence and no social disorders at all; 1-significantly improved, very few symptoms left, occasionally once or twice urinary incontinence, social activity is almost unaffected; 2symptoms alleviated, frequency of urinary incontinence decreased, but still with disability of social activity; 3inefficacy, symptoms do not alleviate at all, no improvement in urinary incontinence, and still with serious social activity disability. The side effects of anticholinergic drugs were divided into peripheral nervous system (PNS) symptoms (dry mouth, dry skin, constipation, and so on) and central nervous system symptoms (mood changes, irritability, overexcitement, mental disorder, and so on). The side effects were recorded as: 0 -no side effects; 1 -light, observed by parents; 2 -mild, observed by patients and parents; 3-severe, cannot be tolerated by patients and parents. After the treatment, all patients were followed for 3 months, and recurrence rate, quality of life, and side effects of drugs were measured and recorded.

\section{Statistical analysis}

SPSS V.16.0 software package was used for statistical analysis. $\chi^{2}$ test was used to compare the means of the two groups. Values with $\mathrm{p}<0.05$ were considered statistically significant.

\section{RESULTS}

A total of 668 cases were included in this study with 334 patients in each group $(p=0.72)$. Patient subgroups were identified a priori using demographic characteristics (age, sex, course of disease) for exploratory analyses (table 1). The results showed that tolterodine was safe and well tolerated. For children with disease-onset duration less than 1 month, tolterodine had very rapid effects, and it took only 4-5 days for a complete remission of all symptoms. Only eight cases recurred. No cases with serious safety concerns were identified. In the tolterodine group, 70 children required prolonged therapy up to 3 months (table 2). The symptoms of detrusor overactivity were completely resolved or significantly improved for $80 \%$ of the patients in the tolterodine group and $37 \%$ in the belladonna mixture group $(\mathrm{p}<0.000)$. Other patients with no improvements were treated with double dose for another 1-3 months.

The results showed significant differences in side effects of PNS and central nervous system between the two groups (table 3). The tolterodine group showed very few side effects. Two cases stopped the treatment because of overexcitement in the night; six cases suffered from constipation. For the belladonna mixture group, the main side effects were insufferable dry mouth and

Table 2 Efficacy of tolterodine versus belladonna mixture

\begin{tabular}{llccc}
\hline Groups & Cured & Significantly improved & Partially improved & No improvement \\
\hline Tolterodine & $142(43 \%)^{*}$ & $122(37 \%)^{*}$ & $64(19 \%)^{*}$ & $6(2 \%)^{*}$ \\
Belladonna mixture & $62(19 \%)$ & $58(18 \%)$ & $106(32 \%)$ & $108(32 \%)$ \\
\hline
\end{tabular}

${ }^{*} \mathrm{P}<0.001$. 


\begin{tabular}{lcc}
$\begin{array}{l}\text { Table 3 } \\
\text { groups }\end{array}$ & Side effects of tolterodine and belladonna mixture \\
\hline Grading & Tolterodine (n) & Belladonna mixture (n) \\
\hline 0-none & 280 & $31^{\star}$ \\
1-light & 46 & $72^{\star}$ \\
2-mild & 6 & $105^{\star}$ \\
3-severe & 2 & $126^{\star}$ \\
\hline
\end{tabular}

${ }^{*} \mathrm{P}<0.001$

eyes, constipation, mood changes, irritability, and so on, which exhibited in $69 \%$ of total patients $(\mathrm{p}<0.001)$, but no patients abandoned belladonna mixture and turned to use tolterodine during the study.

The 3-month follow-up showed a significant treatment effect based on parental assessment of treatment benefit. Among parents of children who received tolterodine therapy, $89 \%$ reported a significant improvement of life quality, including social skills, self-confidence, better mood, and emotional stability, while only $35 \%$ in the belladonna mixture group reported such improvements.

\section{DISCUSSION}

Although the exact etiology of $\mathrm{OAB}$ is unknown to date, pharmacological therapy has been targeted to both the central nervous system and PNS. Acetylcholine is the primary excitatory neurotransmitter involved in bladder (detrusor) contraction and emptying. ${ }^{7}$ Therefore, muscarinic receptors, a kind of acetylcholine receptor, are potential PNS targets. Tolterodine is a bladder-selective muscarinic receptor antagonist. ${ }^{8}$ As competitive $\mathrm{M}$ choline receptor blocker, it is metabolized into a 5-hydroxymethyl derivative by the liver after oral administration. It competitively inhibits the binding of acetylcholine to its receptor, thereby inhibiting the involuntary contraction of the bladder, and can relieve urinary frequency, urinary urgency and urgency incontinence caused by excessive bladder activity. Tolterodine is widely used in adults with urinary incontinence and OAB. ${ }^{9}$ There are many reports on the tolerability, safety and efficacy of tolterodine in adult patients. ${ }^{1011}$ In 2000 , Goessl et al first reported the effects of tolterodine in children with reduced functional bladder capacity and/or detrusor hyperactivity, and there are also reports on the usage of tolterodine in children with $\mathrm{OAB}$ afterwards. ${ }^{12}$ In 2006, Kilic et al reported treatment of children with detrusor instability with tolterodine that shows significantly better tolerability. ${ }^{13}$ In 2008 , Reddy et al found that tolterodine formulations were effective and well tolerated in children with neurogenic detrusor overactivity. ${ }^{14}$ Traditionally, detrusor hyperactivity was treated with anticholinergic drugs, such as propantheline, atropine, anisodamine, belladonna mixture, and so on, in China. Similar to other anticholinergic drugs, belladonna mixture mainly combines with cholinergic receptors $(\mathrm{M}$ receptor muscarinic cholinergic receptors, $\mathrm{N}$ receptor
N1 receptor autonomic nerves, and adrenal medullary cell membrane N2 receptor skeletal muscle receptors), thus antagonizing cholinergic effects. However, belladonna mixture is limited by the lack of bladder receptor selectivity. When they react on the cholinergic receptors in the bladder, the secretion of other glands is also affected, which leads to side effects such as dry mouth, constipation, mood changes, irritability, and so on. ${ }^{15}$ Moreover, there is no confirmed efficacy reported, thus no prevalent adoption in the clinic. Oxybutynin is also a traditional treatment choice, but the side effect could occur four more times in children than adults, ${ }^{16}$ which leads to more than $10 \%$ of patients intolerable and discontinued the treatment. ${ }^{17}$ In the belladonna mixture group, children usually could not maintain the treatment because of the side effects after 1 week of therapy. Severe dry mouth, drinking too much, and urinary micturition occurred. Other side effects like severe constipation and aprosexia could also lead to early discontinuation of therapy. Tolterodine, however, has a high selectivity on the cholinergic receptors in the bladder. The animal experiments show that the drug levels of tolterodine in parotid are only $1 / 8$ of oxybutynin. ${ }^{9}$ In the present study, tolterodine showed a high tolerability in children. Only 2 of the 334 cases discontinued treatment early because of the overexcitement during the night and insomnia; and six cases had constipation. However, the belladonna mixture group showed a high rate of the side effects, and many parents decided to deduce/cease dose, which influences the final efficacy.

Children with voiding dysfunction are usually diagnosed via radiology, urodynamic test or cystoscopy. ${ }^{18}$ In recent years, these methods were well challenged, ${ }^{17}$ mainly because they contribute very little to the final outcome. Also some authors argue that voiding dysfunction can be diagnosed through a careful history collecting and physical examination. ${ }^{19}{ }^{20}$ In our study, under a thorough regular outpatient exam, excluding the anatomical and nerval abnormity, most patients have excellent outcomes after the therapy. The advantages for the diagnosis and treatment modality in this study were low cost, no absence from school during therapy, and perfect cooperation from parents.

The starting dose and duration of the tolterodine therapy remain controversial. Nijman et al reported a 12-week treatment with $2 \mathrm{mg}$ every day. ${ }^{21}$ Also, Reinberg et al suggested to start with a dose of $2 \mathrm{mg}$ per day, and changing the dose depends on the efficacy. ${ }^{22}$ Munding et al started with $4 \mathrm{mg}$ per day (8my maximum) with an average duration of 5.2 months. $^{23}$ In our study, during the first 2 weeks, we give patients $1 \mathrm{mg}$ each time, twice a day. Eighty per cent of them (167/334) reported an excellent outcome, and the others increased the dose to $2 \mathrm{mg}$ each time, twice a day. Eighty-nine per cent of them reported a significant improvement in life quality. So use of tolterodine should not be restricted by time, it could prolong up to 3 months or more if necessary. 
The limitation of this study was that belladonna mixture had strong side effects, most patients had difficulty finishing the course of treatment, which influences the final efficacy.

In conclusion, tolterodine had better tolerability and efficacy than belladonna mixture in treating $\mathrm{OAB}$ in children.

Contributors ZX, DW and DT designed the study. ZX, DW and CT collected the data and contributed to the data analysis and interpretation. JZ and ZZ collected and analyzed the data. All authors approved the final version of the paper.

Funding The authors have not declared a specific grant for this research from any funding agency in the public, commercial or not-for-profit sectors.

Competing interests None declared.

Patient consent for publication Not required.

Ethics approval This study was approved by the Ethical Committee, Zhejiang University School of Medicine (No 2016-128).

Provenance and peer review Not commissioned; externally peer reviewed.

Data availability statement Data may be obtained from a third party and are not publicly available. All data relevant to the study are included in the article or uploaded as supplementary information.

Open access This is an open access article distributed in accordance with the Creative Commons Attribution Non Commercial (CC BY-NC 4.0) license, which permits others to distribute, remix, adapt, build upon this work non-commercially, and license their derivative works on different terms, provided the original work is properly cited, appropriate credit is given, any changes made indicated, and the use is non-commercial. See: http://creativecommons.org/licenses/by-nc/4.0/.

\section{REFERENCES}

1. Greenfield SP. Tolterodine for the treatment of daytime incontinence in children. J Urol 2005;173.

2. Mitsuru K, Katsumi I, Akihiro U, et al. The micturition habits and prevalence of daytime urinary incontinence in Japanese primary school children. The Journal of Urology 2004;171:403-7.

3. Curran MJ, Kaefer M, Peters C, et al. The overactive bladder in childhood: long-term results with conservative management. $J$ Urol 2000;163:574-7.

4. Bauer SB. The Hinman syndrome. J Urol 2017;197:132-3.

5. Saarikoski A, Koppeli R, Salanterä S, et al. Voiding school as a treatment of daytime incontinence or enuresis: children's experiences of the intervention. J Pediatr Urol 2018;14:56.

6. Chen DH, CG W, Zheng WD. Preparation method improvement and stability study of belladonna mixture. Pharmacy Today 2012;22:277-8.
7. Wenske S, Van Batavia JP, Combs AJ, et al. Analysis of uroflow patterns in children with dysfunctional voiding. J Pediatr Urol 2014;10:250-4

8. DuBeau CE, Morrow JD, Kraus SR, et al. Efficacy and tolerability of fesoterodine versus tolterodine in older and younger subjects with overactive bladder: a post hoc, pooled analysis from two placebocontrolled trials. Neurourol Urodyn 2012;31:1258-65.

9. Serels SR, Appell RA. Tolterodine: a new antimuscarinic agent for the treatment of the overactive bladder. Expert Opin Investig Drugs 1999;8:1073-8

10. Marencak J, Cossons NH, Darekar A, et al. Investigation of the clinical efficacy and safety of pregabalin alone or combined with tolterodine in female subjects with idiopathic overactive bladder. Neurourol Urodyn 2011;30:75-82.

11. Angulo J, Rejas J, Linden K, et al. Cost-Effectiveness of Fesoterodine and tolterodine for the treatment of overactive bladder with urge urinary incontinence in Spain and Finland. Value in Health 2013;16.

12. Goessl C, Sauter T, Michael T, et al. Efficacy and tolerability of tolterodine in children with detrusor hyperreflexia. Urology 2000;55:414-8.

13. Kilic N, Balkan E, Akgoz S, et al. Comparison of the effectiveness and side-effects of tolterodine and oxybutynin in children with detrusor instability. Int J Urol 2006;13:105-8.

14. Reddy PP, Borgstein NG, Nijman RJM, et al. Long-Term efficacy and safety of tolterodine in children with neurogenic detrusor overactivity. J Pediatr Urol 2008;4:428-33.

15. Logan BA, Correia K, McCarthy J, et al. Voiding dysfunction related to adverse childhood experiences and neuropsychiatric disorders. $J$ Pediatr Urol 2014;10:634-8.

16. Medhi B, Mittal N, Bansal D, et al. Comparison of tolterodine with standard treatment in pediatric patients with non-neurogenic dysfunctional voiding/over active bladder: a systematic review. Indian J Physiol Pharmacol 2013;57:343-53.

17. Nijman RJM. Classification and treatment of functional incontinence in children. BJU Int 2000;85:37-42.

18. Weber B, Pippi Salle JL, Buffett A, et al. 821 responsiveness of the dysfunctional voiding symptom score in children undergoing biofeedback: analysis of data from a randomized controlled trial. $J$ Urol 2011;185

19. Palmer LS. Evaluation and targeted therapy of voiding dysfunction in children. Urology 2016;92:87-94.

20. Soygür T, Arikan N, Tokatli Z, et al. The role of video-urodynamic studies in managing non-neurogenic voiding dysfunction in children. BJU Int 2004:93:841-3.

21. Nijman RJM, Borgstein NG, Ellsworth P, et al. Tolterodine treatment for children with symptoms of urinary urge incontinence suggestive of detrusor overactivity: results from 2 randomized, placebo controlled trials. J Urol 2005;173:1334-9.

22. Reinberg $\mathrm{Y}$, Crocker $\mathrm{J}$, Wolpert $\mathrm{J}$, et al. Therapeutic efficacy of extended release oxybutynin chloride, and immediate release and long acting tolterodine tartrate in children with diurnal urinary incontinence. J Urol 2003;169:317-9.

23. Munding $\mathrm{M}$, Wessells $\mathrm{H}$, Thornberry $\mathrm{B}$, et al. Use of tolterodine in children with dysfunctional voiding: an initial report. J Urol 2001:165:926-8. 